\title{
Organization Structure research of vocational school's comprehensive quality evaluation system
}

\author{
Huidong Lu ${ }^{a}$, Wenhong Chen \\ Wuhan Mechanical College, Wuhan, 430075, China \\ ahuidong_lu@163.com
}

\begin{abstract}
It's important to establish overall quality of education in schools and comprehensive quality evaluation. In this paper, the evaluation method of students' comprehensive quality is established according to vocational schools. The workflow to implement the specific evaluation is also established. In order to improve the evaluation's results, three measures have been included. The first measure is "learner-oriented, harmonious development" concept, the second one is the principle of fairness, and the third one is the channels of communication smoothly.
\end{abstract}

Keywords: overall quality of education; comprehensive quality; evaluation workflow.

\section{Introduction}

Established a comprehensive quality evaluation system for students in vocational schools reasonably and properly, it's important to establish overall quality of education in schools and comprehensive quality evaluation. And it's also an important guarantee to realize the target of school quality of quality-oriented education. Therefore, to the student's comprehensive quality evaluation in fair, just and open manner, it's necessary to establish effective system and regulations.

\section{The problem of evaluation}

\subsection{Definition is ambiguous.}

The definition of education evaluation is extensive which includes student evaluation, course evaluation, school evaluation, project evaluation, and personnel evaluation. Personnel evaluation includes teacher and other staff evaluation. What's more, there are teaching supervision evaluation and education policy evaluation. Student evaluation is as important as teacher evaluation. The level of teaching has been increasingly concerned and emphasized by some vocational schools, but the student's comprehensive quality is always ignored. There is an argument that teacher is the main participants and implementers of teaching, and the students' comprehensive quality is increasing when the teaching level is improving and learning effect of student is good. And then, the students' comprehensive quality is taken as the result of teaching evaluation or the score of courses.

\subsection{Content is one-sided.}

Do the students comprehensive quality is based on the level of training objectives, which includes theory knowledge, operation skills, moral quality, cultural quality, professional quality, physical fitness, psychological quality, and so on. In fact, the students' comprehensive quality only includes the score of course exam, the score of conduct and record of attendance. Moral quality and professional quality are always ignored, and theory knowledge has been put more importance. Therefore, the progress of evaluation does not base on "Ability standard".

Students are excluded from the evaluators. Quantified evaluation indicators, such as scores, are always as indicators. But, qualitative indicators not, such as learning attitude, psychological quality. The evaluation result is from bystanders (Experts, administrative staff).

\subsection{Evaluation criteria and methods are too simple.}

The evaluation subjects are assumed as simple and same ones, with the same common evaluation standard. The evaluation methods include daily observations, written questionnaire and data analysis. The evaluation results are always in the form of data and simple words. 


\subsection{The evaluation pays more attention to terminative results.}

Evaluators pay more attention to external behavioral objectives and then to teaching results. The scores of learning are used to indicate the whole process of learning, the development of attitude and motivation of learning are ignored. Questionnaires are with questions and objectivity as the main form with unique standard answers. Therefore, the beholder of evaluation just focuses on cognition and behavior objectives, and they try to measure and identify the problems in teaching and managing.

\section{The organization of evaluation}

Educational Administration Section (EAS) of a vocational school is responsible to assess and evaluate students' comprehensive quality, and the department is the basic unit to carry out the evaluation. The process of evaluation is shown as Fig.1.

Step1. To establish the leading group of students comprehensive quality assessment. The membership is director of the department, Secretary of the party branch, deputy directors of the department, Class instructors.

Step2. To establish detailed rules for the implementation of the department.

Step3. To evaluate each student of a class which is in responsible of the class instructor. And the progress is listed in the following:

- Each student write personal self-assessment summary of a whole term.

- Each student is evaluated by the assessment group of classes, which includes review the self-assessment summary and marks it.

- The evaluation marks are showed to each student of class, and commented by others.

- The evaluation results are confirmed after the public notice.

Step4. To evaluate the comprehensive quality each term and deposit and archive the evaluation results after confirmed by students themselves.

Step5. To summary all the comprehensive quality evaluation results of two years or three years' before graduation, and then, to rank the final performance of each student in a class. EAS is responsible to audit the final results.

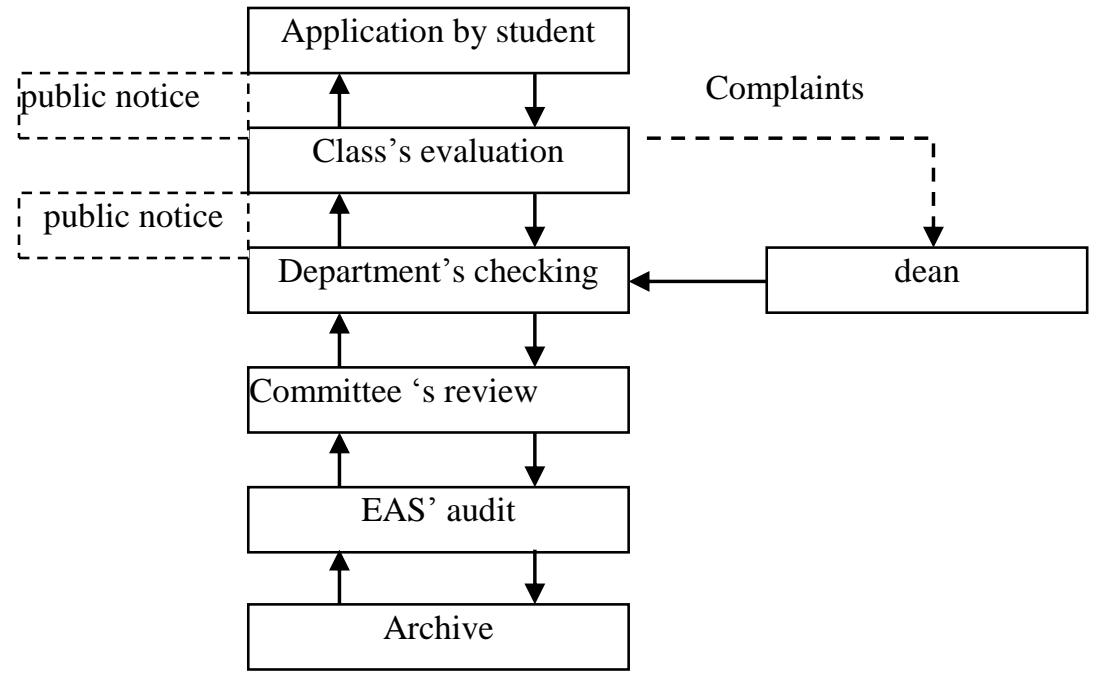

Fig1. Process of evaluation

"Application by student" is students reporting performance and applying for evaluation.

"Class' evaluation" is students evaluating themselves together with each other. The results must be shown to all students in public method. Students have right to complaint the results to leaders of the department.

"Department's checking" is the evaluation results being collected and checked by the office of department.

"Committee's review" is the evaluation committee reviewing the results, and the committee always includes teachers and manages staff. 
"EAS' audit" is Educational Administration Section auditing the results of the whole school.

"Archive" is the evaluation result being archived as files.

"Public notice" is the result must be shown to every student in public method.

\section{4. the principle of evaluation}

\subsection{Establish "learner-oriented, harmonious development" concept.}

The staff of vocational school should renew the education concept, and set up activities and platforms as the as much as possible for students ' comprehensive qualities development. Students can develop their personality, improve adaptability, creativity and practice ability. And then, the student comprehensive quality can develop harmoniously and balance with each other. The comprehensive quality evaluation has the basic data.

\subsection{Be democracy, equitable, fair and reasonable.}

The principle of public notice should be set up. The contents, methods, process of evaluation must be shown as public notice in advance. Before each evaluation, the membership of evaluation committee must be shown in public notice. The evaluation results must be sent to every student. If there are students who have questions about the result, the leaders of department are responsible to deal with it. The reporting and complaint system should be set up, too. The vocational school should set up reporting lines, students, teachers or others who doubt about the fairness of contents, methods, process and results. This kind of reporting is mainly dealing with by the department.

\subsection{Build an effective communication channel}

Student's comprehensive quality evaluation involves a large amount of people's cooperating, such as teachers, students, staff offices. Therefore, effective communication channels are important for each one involving in the evaluation, and the evaluation information can be transmit and feedback to each one, and then, the students comprehensive quality evaluation can be processed smoothly.

\section{Summary}

The student's comprehensive quality evaluation involves in EAS, advocacy section, practice management section and teaching evaluation office. EAS deals with student's comprehensive quality assessment, students ' learning achievement assessment and evaluation. Practice management section deals with students' job adaptability and the development of skills, basing on the employer's demand for talents. The advocacy section deals with training platform for students' exercise and practicing. All the membership of "students comprehensive quality evaluation Commission" are responsible for evaluating student's comprehensive quality as communication channels timely.

\section{References}

[1] Zubing Luo, Predicaments of Analytical Evaluation on High School Students' Comprehensive Quality and Its Countermeasures, Education Science, Vol. 30 (2014), p.7-12.

[2] Jiuquan Yang, The dilemma and outlet of synthetic evaluation of quality education, Journal of East China Normal University (Education Sciences), Vol. 22 (2013), p.52-55.

[3] Xiaoling SUN, Ning WANG, Evaluation of comprehensive quality of college students based on intuitionistic fuzzy sets, Journal of Hefei University of Technology (Natural Science), Vol. 36 (2013), p.1002-1005.

[4] Zhisong ZHANG, Practical Problems and Feasible Strategies of Comprehensive Quality Evaluation, Journal of Zhejiang Normal University (Social Sciences), Vol. 41 (2016), p.107-110. 